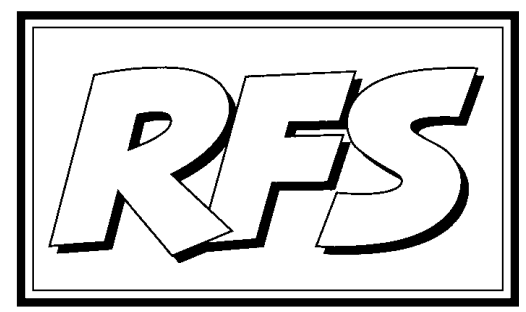

Revista de Fomento Social, 56 (2001), 303-307

\title{
Dos reacciones de urgencia ante los atentados terroristas en Estados Unidos
}

\section{Posición de INTERMÓN OXFAN ante los ataques te- rroristas contra Estados Unidos}

Compartimos el dolor. INTERMÓN OXFAM reafirma su condena a los atentados terroristas Ilevados a cabo en Estados Unidos el pasado 11 de septiembre. Nos sentimos próximos a las víctimas y compartimos con sus familias y amigos el terror por los hechos y el dolor y la tristeza por sus consecuencias. Queremos hacer llegar a toda la población norteamericana nuestra solidaridad, a través de nuestra organización hermana OXFAM América. La violencia es detestable y resulta más intolerable aún cuando se utiliza de forma masiva e indiscriminada contra población civil.

Alianza contra el terrorismo. Creemos que la captura y juicio a las personas y organizaciones que estén detrás de los atentados debe hacerse a partir de una estrecha cooperación internacional que forme una alianza contra el terrorismo. Tanto el alcance de las actuaciones como los medios 
para desarrollarlas deben llevarse a cabo bajo el mandato de Naciones Unidas y estar basadas en el derecho internacional. Estos hechos ponen de manifiesto la imperiosa necesidad de fortalecer la legislación internacional y los mecanismos para aplicarla, como el Tribunal Penal Internacional.

No más víctimas civiles. Estos hechos no deben dar lugar a un ataque indiscriminado, por parte de Estados Unidos y sus aliados de la OTAN, en el que se vea involucrada más población civil inocente. Estamos en contra de cualquier respuesta que provoque más muertes inocentes, que al sufrimiento añaden el odio que alimenta el círculo vicioso de la violencia. El terrorismo sólo será superado si se rechaza la cultura de la violencia y la venganza y se avanza hacia una cultura de la paz basada en la justicia.

Derecho a la asistencia humanitaria. Como organización humanitaria, reivindicamos el derecho de todas las personas a recibir atención humanitaria y nuestro deber y derecho de proveerla. El derecho humanitario es también parte del derecho internacional $y$, por ello, ninguna respuesta al sabotaje terrorista puede implicar la reducción de la ayuda a las víctimas de conflictos o desastres humanitarios. Lo anterior es especialmente válido para Afganistán, donde la situación humanitaria es dramática. De este país, donde OXFAM INTERNACIONAL trabaja desde 1989, han huido ya más de cuatro millones de personas a causa de la guerra y la pobreza, y la supervivencia de otros tres millones dentro del país (desplazados internos y población vulnerable) depende directamente de la ayuda internacional.

Por la convivencia entre culturasy religiones. Los sucesos de Nueva York y Washington constituyen un atentado terrorista que escapa al esquema de la guerra convencional. Creemos que las declaraciones que hablan de guerra contra un enemigo impreciso, y que generalizan una pretendida "bondad" del mundo occidental frente a otras culturas, contribuyen a crear un clima de demonización del Islam y de sus mil millones de seguidores en el mundo, en su mayoría pacíficos. Este clima puede tener consecuencias muy graves en términos de incremento del racismo, exacerbación de conflictos, y aumento de la intolerancia, que deben rechazarse.

Prevención y resolución de todos los conflictos. La comunidad internacional se ha distanciado o ha olvidado numerosos conflictos activos en el mundo, que producen miles de víctimas, en su mayoría civiles, y que cada vez reciben menos atención en la agenda política internacional. Sin embargo, estos conflictos se encuentran conectados al resto del mundo a través del comercio ilícito de diamantes y petróleo, del tráfico de armas y de los 
paraísos fiscales. Controlar este comercio para no alimentar los conflictos se debe convertir en una prioridad, y la comunidad internacional debe ser mucho más activa en la prevención y resolución de conflictos, para garantizar la vida y la seguridad de todos.

Papel de la Unión Europea. La Unión Europea debe jugar un papel relevante en la resolución de esta crisis, de forma solidaria con las víctimas del terror y reflexiva respecto a las actuaciones a llevar a cabo ahora. La solidaridad con el pueblo estadounidense no debería llevar a Europa a secundar cualquier actuación que se emprenda desde Estados Unidos, especialmente si incluye acciones violentas contra población civil. Europa, y España en particular, debe promover la estabilidad en la región mediterránea, propiciando un espacio de convivencia pacífico y próspero, entre razas y culturas.

Por una paz basada en la justicia. Como organización humanitaria y de cooperación para el desarrollo, tenemos una larga experiencia de trabajo cerca de las poblaciones que viven en la pobreza. Sabemos de su capacidad de iniciativa y de su esfuerzo por salir adelante, pero también conocemos su sufrimiento y su dolor. Los atentados en Estados Unidos, aunque deben ser analizados desde la perspectiva del terrorismo internacional, deben llevarnos también a reflexionar sobre cómo conseguir un mundo seguro y justo. Es crucial analizar y trabajar sobre las causas que generan pobreza e injusticia para promover una globalización inclusiva, que no genere mayores fracturas y desequilibrios, y asegure el derecho de todos a una vida digna.

Septiembre 2001

\section{Reacción de EURO INFOS: Buscando la justicia}

El 11 deseptiembre de 2001 ha cambiado el mundo. Los ataques terroristas sobre Nueva York y Washington mataron a miles de personas y dejaron estupefacto al mundo entero. La tragedia humana fue inmensa, pero los efectos de tamaña maldad podrían ser mayores. Al mismo tiempo, sin embargo, cabe un pequeño resquicio para la esperanza de que, como 
resultado de todo esto, podamos mejorar un poco el mundo.

Maldad es la palabra exacta para describir lo ocurrido. Como cristianos, reconocemos que el mal existe en el mundo y en cada uno de nosotros, aunque en muy pocas ocasiones sentimos la necesidad de usar esa palabra para calificar los actos de los seres humanos nuestros prójimos. Pero no hay duda alguna de que el asesinato de tantas personas inocentes en el Centro Mundial del Comercio y en el Pentágono, para no mencionar a los de los aviones suicidas, es un acto de pura maldad.

El asesinato, incluso el asesinato masivo, es desgraciadamente algo demasiado familiar en el mundo moderno. Cada día la gente es víctima del terrorismo en diferentes regiones. Deberíamos quedar espantados por tales atentados, y orar también tanto por las víctimas cuanto por los que los perpetran.

Las atrocidades de los Estados Unidos no son un hecho aislado, pero las dimensiones de esta tragedia la hacen excepcional. La enormidad de este crimen lo coloca más allá de los parámetros de nuestros sistemas de justicia. Aceptamos que todo crimen debe ser castigado, pero ¿a qué justicia servimos si la represalia sólo conduce a una espiral imparable de violencia y de sufrimiento humano?

En el corazón mismo de la concepción cristiana de justicia está la reconciliación. Mostrando arrepentimiento y -si es posible- corrigiendo lo que se ha hecho mal, podemos reconciliarnos con aquellos a los que hemos ofendido y con nuestro Dios. Pero si el castigo sólo conduce al resentimiento y a la agresión, entonces no se realiza la auténtica justicia. Ésta no es simplemente una verdad objetiva: es una lección muy pragmática para un futuro de paz en el mundo.

Podemos esperar y orar para que la "larga guerra" de represalias por los ataques en Estados Unidos sea justa y correcta. Podemos urgir a nuestros líderes que así lo garanticen. Como personas, podemos también contribuir a colaborar para que las relaciones entre distintas comunidades nacionales y religiosas se refuercen a través de este dolor común, en vez de que aumente la tensión entre ellas a fuerza de sospecha y de temor mutuos.

Y una cosa más podemos hacer. Podemos tomar esta oportunidad para construir un sistema que garantice una auténtica justicia en nuestro mundo. No hay causa capaz de justificar la carnicería que ha castigado a los Estados Unidos el 11 de septiembre. Ahora bien, tenemos que reconocer que vivimos 
en un mundo donde la injusticia y la pobreza son endémicas; donde se niega a miles de millones de personas la libertad y la prosperidad que nosotros vivimos en Occidente; donde la religión puede ser pervertida hasta llevar a la gente a cosas terribles.

Para algunos los ataques en Nueva York y Washington representan un golpe contra el dominio económico y militar. Pero recordemos que la mayor parte de las personas que trabajaban en el Centro Mundial del Comercio -de muchos países, y no sólo de los Estados Unidos- veían el libre comercio como el mejor camino para la prosperidad de todos; y la mayoría de los que trabajaban en el Pentágono consideraban que estaban contribuyendo con ello a la paz mundial.

Ahora, más que nunca, es el momento de hacer frente a la exclusión, injusticia y pobreza actuales de forma que nadie pretenda encontrar justificación en ninguna otra ocasión para perpetrar una maldad semejante. Es el momento también de establecer un sistema de gobierno global que ayude a los pobres, proteja a los débiles y permita vivir a todos en una genuina igualdad y paz, cualquiera que sea su nacionalidad, su religión, su origen étnico y su inclinación política. Esa sería la auténtica justicia. 